\title{
LUKISAN DINDING GOA SEBAGAI SALAH SATU UNSUR UPACARA KEMATIAN
}

\section{Oleh: Daud Aris Tanudirjo}

Lukisan dinding gua merupakan salah satu basil budaya Prasejarah yang menarik. Basil budaya ini terdapat di berbagai tempat di dunia, termasuk di Indonesia. Di Indonesia, lukisan dinding gua pada umumnya ditemukan di daerah Indonesia bagian timur, yaitu di Sulawesi, Maluku, Timor dan Irian Jaya. Bentuk-bentuk yang dilukiskan sangat beragam baik yang digambar secara naturalistis, dengan garis-garis sederhana, maupun abstrak.

Meskipun lukisan dinding gua ini merupakan hasil budaya prasejarah yang penting, namun sampai saat ini penelitian dan pembahasan yang cukup mendalam belum banyak dilakukan. Banyak masalah yang masih meliputi hasil budaya ini, misalnya masalah pertanggalan, persebaran, maupun fungsi dan artinya. Menurut Heekeren, lukisan dinding gua di daerah Sulawesi dibuat kurang lebih 4000 tahun yang lalu (Heekeren, 1950 : 30). Sementara itu Roder berpendapat bahwa lukisan-lukisan dinding di Irian Jaya berumur tidak lebih dari 1000 tahun yang lalu (Roder, 1956 : 399). Mengenai arti dan fungsinya sampai saat ini banyak pendapat yang menghubungkan lukisan dinding gua dengan magi perburuan, penolak bala, upacara inisiasi, dan kesuburan (Heekeren, 1972: 118; Roder, 1956 : 388; Soejono, 1963 : 48). Pendapat ini tidak selalu benar karena ada kemungkinan pula bahwa lukisan dinding gua tersebut dibuat sebagai ungkapan seni saja. Untuk menentukan fungsi lukisan dinding gua perlu diperhatikan konteks temuannya.

Salah satu aspek menarik yang berkaitan dengan fungsi lukisan dinding gua adalah ditemukannya lukisan-lukisan pada situs-situs pengubur an, yaitu di daerah danau Sentani, teluk Berau, dan juga di gua-gua di Niah (Sarawak). Lukisan di sekitar danau Sentani terdapat di Gumaimit dan Pinfelu. Bentuk-bentuk yang dilukiskan pada umumnya bersifat abst rak yaitu garis -garis lengkung, lingkaran spiral, dan binatang melata. Di sekitar tempat tersebut ditemukan sisa-sisa mayat yang terutama diletakkan dekat sungai atau danau (Soejono, 1963 :49).

Di daerah teluk Berau, lukisan dinding gua diteliti oleh J. Roder dan dibedakan menurut warna dan gayanya. Menurut warnanya dibedakan menjadi tiga yaitu warna merah, hitam dan putih. Dalam kaitannya 
dengan kronologi, lukisan berwarna merah dianggap tertua, kemudian lukisan berwarna hitam, dan paling muda berwarna putih. Menurut gayanya, Roder membedakan menjadi gaya Tabulinetin, gaya Manga, gaya Arguni, dan Ota I, gaya Ota II dan Sossora, Lukisan gaya Ota II dan Sossora yang dibuat dengan warna hitam adalah lukisan yang terdapat pada situs penguburan di daerah Ota, Sossora, dan gua Dudumunir. Bentukbentuk yang dilukiskan adalah manusia bersikap kangkang dan perahu . Lukisan-lukisan ini terdapat pada serambi gua-gua di tepi pantai yang hanya dapat dicapai melalui taut. Di tempat ini terserak bekas -bekas penguburan. Mayat-mayat dimasukkan dalam peti kayu dan diletakkan di atas perancah bambu. Bekal-bekal kubur diletakkan di bawahnya, kadang-kadang terdapat dayung yang disandarkan pada perancah. Menurut penduduk setempat, posisi tersebut melambangkan perjalanan roh menuju dunia roh. Mengenai hubungan lukisan Ota II dan Sossora dengan penguburan, Roder menulis : 'We can, infact, prove that the black figured rock paintings are contemporaneous with the boat coffins and burial in the surf galleries'. Bukti yang diajukan adalah persamaan gambar pada tempayan di tempat mayat dengan lukisan-luldsan pada dinding gua (Roder, 1956 : 387 - 400), Sayang Roder tidak membahas lebih lanjut, bentuk -bentuk hubungan antara lukisan dinding gua dengan penguburan secara fungsi-onal. Oleh karena itu pada kesempatan ini akan dicoba ditelusuri hubung-an dua unsur budaya tersebut.

Sebagai data tambahan perlu pula dikemukakan bahwa di gua-gua Niah (Serawak) ditemukan pula lukisan dinding gua bersama -sama dengan sisa-sisa penguburan. Lukisan di Niah ini dibuat dengan sederhana berupa garis-garis linear yang meliputi bentuk-bentuk manusia, perahu, dan binatang melata (Harrisson, 1958: 549 -595).

Berdasarkan data yang telah diketemukan, ternyata bentuk-bentuk yang dilukiskan pada situs-situs penguburan meliputi bentuk geometris (lengkungan, lingkaran spiral), perahu, manusia dan binatang melata. Tentunya bentuk-bentuk tersebut mempunyai arti yang berkaitan dengan fungsinya. Sehingga untuk dapat menjelaskan fungsi lukisan dinding gua harus dicari arti bentuk bentuk yang dilukiskan tersebut.

Bentuk geometris. Bentuk geometris seperti lengkung bersambung temyata merupakan lambang-lambang yang mengandung arti tertentu. Lengkung bersambung yang merupakan pilin ganda yang dirangkaik.an pada perisai suku-suku di lrian Jaya ternyata merupakan lambang nenek 
moyang. Perisai tersebut tidak saja dipakai untuk pesta perisai dan perang tetapi juga dipasang di rumah sebagai penolak bala (Adhy Asmara , 1980 : 58). Bentuk-bentuk Igeometris juga disebut sebagai pola magis (magic design) atau lambang totem (Heekeren, 1958: 126; Holt, 1967: 15). Menurut Herbert Read, bentuk geometris yang disusun secara tertentu dapat melambangkan kosmos (Read, tt : 10). Sedangkan suku Aborigin di Australia yang masih melukisan bentuk geometris pada tanah, pohon, maupun senjata mereka, menganggap sebagai perjalanan nenek moyang atau mitologi mereka (Elkin, 1954: 225; Mulvaney,1969: 175).

Perahu. Bentuk perahu merupakan salah satu unsur yang dominan dalam mitologi rakyat Indonesia. Orang Yamdena di Tariimbar (Maluku) beranggapan nitu atau arwah pergi ke dunia rob yang ada di seberang lautan dengan naik perahu (Koentjaraningrat, 1977 : 237). Konsepsi semacam itu juga terdapat pada suku Marind Anim di Irian Jaya. Mereka percaya bahwa orang yang mati rohnya pergi ke dunia roh yaitu tempat matahari tenggelam dengan naik perahu (Hans Daeng, 1963 : 264). Konsepsi ini mirip adegan yang digambarkan di Sossora yaitu perahu berpenumpang yang mengarah pada bentuk matahari (Holt, 1967 : 14, 20 plate 3,14$)$. Bentuk perahu sebagai kendaraan arwah sering digambar sebagai burung, seperti pada masyarakat Dayak (Schaade, 1979: 18). Konsepsi perjalanan arwah dengan perahu tampaknya menjadi konsepsi urnum bangsa Indonesia. Hal ini mungkin dilatarbelangkangi proses migrasi penduduk dengan perahu. Konsepsi tersebut diungkap pula dalam bentuk peti mati maupun hiasan-hiasan bergambar perahu pada perala:tan upacara kematian (Soejono, 1977: 130; Hoop, 1949: 306).

Manusla. Umumnya bentuk manusia yang dilukiskan pada situssitus pengubui:an digambarkan dalam sikap kangkang. Bentuk semacam ini banyak didapatkan pada benda-benda yang berhubungan dengan penguburan. Pada wadah-wadah mayat megalithik seperti waruga di Sulawesi dan sarkopagus di Bali, bentuk manusia kangkang terdapat pula. Selain itu juga pada dolmen di Besuld dan tangkai sendok untuk upacara kematian di Timor. Di Kalimantan, lukisan semacam ini ada pada rumahrumah kematian. Menurut Fraser, disamping mempunyai fungsi menolak bala, hiasan tersebut juga berarti kelahiran kembali (Soejono, 1977 : 138-9). Sebagai -penolak bala, bentuk manusia kangkang dianggap sebagai lambang nenek moyang sendiri yang mempunyai kekuatan sakti. Sehingga dengan menggambarkan nenek moyang tersebut diharapkan didapatkan kekuatan saktinya (Hoop, 1949: 92). Bagi penduduk Irian Jaya, manusia 
Bagi penduduk Irian Jaya, manusia kangkang disebut sebagai matutuo yang berarti nenek moyang agung (The Great Ancestor). Cerita rakyat setempat menyebutkan bahwa nenek moyang itu datang dari arah matahari terbit (Roder, 1956: 400).

Binatang melata. Lukisan bentuk binatang melata pada dinding gua di Irian Jaya sering dibuat dengan digayakan sehingga sulit dikenali bentuk aslinya. Tetapi kebanyakan bentuknya menyerupai kadal, biawak atau bengkarung. bentuk-bentuk semacam ini tidak asing bagi kesenian prasejarah di Indonesia. Di Sulawesi, gambar kadal terdapat pada kalamba, sementera di Besuki dan Sumba terdapat pada tutup peti kubur batu (Soejono, 1977 : 137). Bentuk kadal dianggap sebagai penjelmaan dewa atau nenek moyang, karena ada anggapan bahwa arwah nenek moyang seringkali merasuk ke dalam kadal. Orang Batak selain percaya pada anggapan tersebut, juga mengangga $\mathrm{p}$ kadal sebagai dewa alam bawah dan kesuburan (Hoop, 1949: 222; Holt, 1967 : 14). Lukisan kadal di Pulau Muamuram (Irian Jaya) yang dibuat pada tebing sebuah danau kecil dianggap sebagai seorang raksasa wanita penjaga danau itu, sedangkan danaunya sen diri dianggap sebagai pintu menuju dunia roh (Galis, 1948: 13 - 17).

Berdasarkan pembahasan di atas, jelasfah bahwa lukisan dinding gua yang ada di situs-situ s penguburan mempunyai arti magis-religius. Hal ini tidak mengherank an mengingat bahwa konteks temuannya adalah tem pat penguburan. Lukisan-lukis an tersebut pada pokoknya menceritakan tentang mitologi yang berkaitan dengan nenek moyang. Thema yang dikemukakan pada umumnya adalah tentang perjalanan nenek moyang itu sendiri baik dalam perjalanan ke dunia arwah maupun penjelmaan dan kelahiran kembali .

\section{III}

Untuk menelaah hubungan antara lukisan dinding gua dengan penguburan atau adat perawatan mayat pada umumnya, maka perlu ditinjau konsepsi-konsepsi manusia tentang kematian, Konsepsik itu sendiri tidak dapat dilepaskan dari pemahaman manusia mengenai jiwa, kehidupan sesudah mati, dan alam supernatural, yang merupakan dasar timbulnya upacara-upacara_yang bersifat magis-religius.

Dalam banyak sistem kepercayaan di Indonesia, manusia dianggap mempunyai dua jiwa yaitu jiwa selama manusia hidup dan roh yaitu jiwa manusia sesudah mati. Jiwa selama manusia hidup merupakan kekuatan badannya sehingga manusia mampu berpikir, merasa dan bertindak. Pada waktu manusia mati, jiwa meninggalkan tubuh selama-lamanya dan 
menjadi roh. Roh sering dianggap sebagai kelanjutan jiwa, namun tidak jarang dianggap sebagai unsur kehidupan lain yang aktif setelah manusia mati (Rachmat Subagya, 1981 :87). Adanya perbedaan jiwa dan rob dalam alam pikiran suku-suku bangsa di Indonesia dinyatakan dalam istilah yang digunakan untuk menyebutnya . Pada masyarakat Nias, jiwa disebut noso, dan roh disebut beghu. Orang Batak menyebutnya tondi/sahala dan begu. Orang Dayak Ngaju menyebut aniroe dan adiau. Orang Jawa menyebutnya sebagai nyawa dan arwah. Sementara itu orang Toraja menamakannya tanoana dan angga. Orang Maluku menyebut sebagai smangit dan oitu. Orang Timor menyebut auh/amanhalo dan amanatom, sedang orang Irian mengenal sebagai fonggumu dan kepka/kdo (Rachmat Subagya 1981 : 87; Koentjaraningrat, 1977 : 235). Pemahaman akan adanya roh mencerminkan sikap pengakuan bahwa salah satu unsur kehidupan manusia bersifat abadi. Sebagai akibatn ya manusia membutuhkan suatu penggambaran yang memberikan penjelas an keadaan roh itu selanjutnya.

Umumnya roh yang meninggalkan tubuh digambarkan menuju suatu tempat tertentu . Tempat roh itu sendi ri ber agam di berbagai suku bangsa di Indonesia. Kadang-kadang tempat roh dikatakan ada di seberang lautan, di suatu puncak gunung yang tinggi, di dalam hutan belantara atau di bawah bumi yang haru s dilalui lewat lubang dalam tanah (Koentjaraningrat, 1958 : 188). Tempat roh dibayangkan terletak sangat jauh sehingga roh haru s melakukan perjalanan yang lama untuk mencapain ya (Racmat Subagya, 1981: 194). Tempat rob kemudian sering dikaitkan dengan alam supernatural yaitu alam gaib yang dihuni kekuatan -kekuatan dan mahluk mahluk yang tidak dapat dikuasai oleh manusia dengan cara-cara biasa. Alam ini timbul dari kesa dar an manusia akan ada nya suatu lingkungan yang tidak tampak, yang ada di luar batas pancaind era nya dan di luar batas akalnya. Namun alam itu dira sakan ber peranan dalam kehidupan manusia. Nenek moyang sebagai salah satu unsur dal am alam supernatural dian gga $\mathrm{p}$ masih mempun yai campur tangan dalam kehidupan keturunannya di dunia. Di samping itu konsepsi semacam itu menyiratkan kesadaran manu sia sebagai unsur alamiah yang berasal dari jiwa alam, oleh karena itu akan kembali ke pada ala m itu. (Rachmat Subagya, 1981:87).

Alam supernatural dianggap mempunyai sifat-sifat dan lingkungan yang tidak jauh berbeda dengan dunia tempat manusia hidup. Demikian pula penghuni alam ter sebut dianggap mempunyai sifat yang tidak jauh berbeda dengan manusia. Mereka mempunyai keinginan-keinginan yang harus diperhatikan manusia, jika diabaikan mereka marah dan menimbulkan kerugian bagi manusia. Sehingga timbul rasa takut ter had ap alam supernatural, terutama terhadap nenek moyang. Sebagai akibatnya timbul 
usaha-usaha manusia untuk mengadakan hubungan sebaik-baiknya dengan roh nenek moyang. Hubungan itu dinyatakan dalam berbagai upacara pemujaan roh nenek moyang. Sebaliknya dengan upacara tersebut manusia mengharapkan agar roh nenek moyang memberikan bantuan kepada manusla (Koentjaraningrat, 1958: 188; Firth dkk, 1966: 207).

Dalam perkembangan selanjutnya, upacara-upacara itu tidak lagi sepenuhnya berfungsi sebagai sarana untuk meminta bantuan kepada nenek moyang, tetapi juga merupakan suatu paksaan terhadap nenek moyang . Dengan upacara-upacara, manusia memak sa nenek moyang memenuhi keinginan manusia sesuai dengan tujuan dan maksudnya. Upacara semacam ini disebut upacara magis-rdigius, karena mempunyai unsur magi maupun religi. Magi adalah serangkaian cara yang digunakan manusia untuk memp engaruhi alam sedemikian rupa sehingga manusia dapat mencapai tujuan dan kehendaknya. Menurut Fraser, magi atau ilmu gaib didasarkan pada dua anggapan yaitu :

I. Anggapan bahwa akibat yang akan terjadi mirip dengan penyebabnya. Jika seora ng menu suk sebuah boneka yang merupakan gambaran dari seorang tertentu, maka orang yang dimaksud tersebut akan mend erita seperti boneka itu. Anggapan ini menimbulkan magi tiruan atau 'imit ative ma gic' .

2. Anggapan bahwa sesuatu yang pernah berhubungan dengan sesuatu yang lain, akan tetap mempuny ai hubungan walaupun sudah terpisah jauh. Sehingg a jika orang akan melakukan pembalasan dengan magi, orang tersebut harus mengumpulkan benda -benda yang pernah dipakai atau berhubungan dengan orang yang akan dibalas. Kemudian benda-benda ters ebut dimusnahkan, maka orang yang dimaksud akan menderita. Magi semacam ini disebut magi kontak atau 'contagious magic' (Koentjaraningrat, 1977 : 276 - 8, Baal, 1977: 56).

Sementara itu, religi adalah ketergantung an manu sia pada kekuatankekuatan alam supernatural (Firth dkk., 1966 : 183). Jadi upacara magis religius adalah upacara yang memakai magi atau ilmu gaib, namun masih mendasarkan pada keperca yaa $\mathrm{n}$ akan kekuasaan alam supernatural.

Upacara kematian adalah salah satu upacara yang bersifat magis religius. Berdasarkan pemahaman manusia akan jiwa dan roh, maka kematian dapat dilihat sebagai proses perpindahan dari suatu kedudukan dim masyarakat dunia menuju kedudukan dalam masyarakat alam supe rnatural atau tempat roh. Kenyataan ini telah dibuktikan dengan hasil penelitian Hertz tentang upacara kematian di lndoAesia. Dalam penelitiannya Hertz berhasil menghimpun anggapan-anggapan yang mendasari 
upacara kematian yang juga didapatkan pada upacara inisiasi. Anggapananggapan tersebut ialah :

1. Anggapan peralihan dari suatu kedudukan dalam suatu masyarakat ke masyarakat lain adalah suatu masa krisis, baik bagi individu maupun masyarakat.

2. Anggapan bahwa obyek inisiasi itu, dalam upacara kematian adalah orang yang mati, adalah mahluk yang sakral.

3. Anggapan bahwa peralihan kedudukan itu tidak dapat berlangsung sekaligus, tetapi bertahap.

4. Tahapan itu.terdiri dari tiga tahap, sesuai dengan upacara inisiasi, yaitu melepas hubungan individu dari masyarakat mempersiapkan individu bagi kedudukan baru dan mengangkat individu ke dalam kedudukan baru .

5. Anggapan bahwa pada tingkat persiapan dari masa inisiasi, individu adalah mahluk yang Iemah, sehingga perlu dikuatkan dengan berbagai upacara ilmu gaib (Koentjaraningrat, 1958: 190).

Berdasarkan anggapan-anggapan itu sangat jelas bahwa magi merupakan unsur penting dalam upacara kematian. Upacara kematian bersifat magis karena upacara ini dianggap sebagai sarana magis untuk menjamin roh selamat dalam perjalanan menuju ke tempat rob atau menjamin agar kenaikan kedudukan dari status jiwa ke status rob berjalan lancar. Sedangkan pada sisi lainnya, upacara kematian bersifat religius. Dalam upacara ini manusia memohon pertolongan dan perlindungan alam supernatural agar mereka dapat melewati masa krisis (Rachmat Subagya, 1981: 194; Firth dkk., 1966: 209).

Dalam upacara kematian, pada umumnya sarana untuk menjamin agar roh orang yang mati sampai di tempat tujuan dengan selamat, atau agar tahap perpindahan berjalan lancar dilakukan dengan magi tiruan . Magi pada umumnya mempergunakan mitologi sebagai acuan. Hal ini dapat dilihat dalam tatacara menempatkan mayat atau adat perawatan mayat, dan ritus upacara kematian. Jika di dalam mitologi roh digambarkan pergi ke seberang Jaut, maka mayat akan ditempatkan pada sebuah perahu atau peti mati berbentuk perahu, dan diletakkan mengarah ke taut. Jika roh dianggap menghuni pohon, maka mayatnya akan diletakkan di pohon. Bila ada gambaran bahwa manusia berasal dari abu maka mayatnya akan diperabukan. Sementara itu penanaman jenazah pada umumnya didasarkan pada anggapan bahwa roh menuju ke tempatnya di dasar bumi (Rachmat Subagya, 1981: 194 --5). Demikian pula anggapan bahwa proses kematian adalah tahapan berpindahnya kedudukan manusia dinyatakan dalam upacara penguburan kedua (secondary burial). Cara penguburan kedua ini terdiri dari tiga tahap yaitu pemakaman sementara atau se- 
pulture proviselre, masa antara atau periode inter-mediaire yang dapat ber langs ung beb era pa tahun, dan upacara terakhir atau ceremonie finale (Koentjaraningrat. 1958: 191 - 2). Bukti dilakukannya penguburan kedua ini antara lain tampak pada sistem penguburan di Gilimanuk (Soejono, 1977: 188), dan Melolo (Heekeren, 1972: 194). Data yang dikemukakan di atas memberikan gambaran yang nyata bahwa upacara kematian sebenarny adalah pementasa $n$ kembali mitologi nenek moyang atau pun anggapan anggapan tentang kematian. Hal itu tidak mengherankan karena dalam pola pemikiran magis, mitologi akan memberikan manfaat jika dicerita kan kembali. Penceritaan mitologi dianggap memberikan kekuatan pada manu sia unt uk tahan dalam penderitaan dan selamat melalui masa krisis (Koentjaraningra t, 1977 : 255; Rachmat Subagya, 1981 : 116). Cara menceritak an kembali mitologi dapat dipentaskan dengan drama dalam uppacara-upacara, namun tidak jarang diungkapkan dalam nyanyian atau syair (Koentjar aningrat, 1977: 255; Peursen , 1976: 40), bahkan di bebera pa tcmpat dengan dilukiskan.

Jika anggapan -anggapa $\mathrm{n}$ terse but diterapk an pada lukisan dinding gua dan adat peraw atan rnayat, maka hubungan kedua unsur kebudayaan itu menjadi jelas. Keduanya merupakan bagian penting dalam upacara kematia n. Dapat diperkirakan, ketika penempatan mayat dilakukan diser tai pula denga n pembuatan lukisan dinding gua sebagai usaha pence ritaan mitologi nenck moyang.

Lukisan -lukisan bentuk perah u dan manusia kangkang yang terdapat pada gaya Ota 11 dan Sossora menceritakan mitologi tersebut . Lukisanlukisan itu dimaksudkan sebag ai magi tiruan untuk menjamio roh orang yang mati dapat sampai di tempat roh dengan selamat. Hal itu masih juga diperkuat dengan membuat bentuk peti mayat seperti perahu. Sementara itu, lukisan geometris di sekitar Danau Sentani, yang dianggap sebagai lambang totem atau kisah perjalanan nenek moyang, adalah magi tiruan yang menjamin roh berhasil kembali ke sumber totem. Memang dalam faham totemisme ada angga pan bahwa segala aspek kehidupan berasal dari sumb er totem yang digambarkan berupa gejala alam seperti tumbuh an, binatang, atau benda-benda lainnya. Orang Aborigin di Australia, misalnya menganggap bahwa seorang yang meninggal rohnya akan kembali ke asalnya yaitu pusat totem (Elkin, 1954 : 319 -320).

Untuk memberikan gambaran yang lebih jelas tentang hubungan lukisan dinding gua dengan adat perawatan mayat dalam upacara kematian, perlu dikemukakan beberapa data etnografis sebagai pembanding.

Di kalangan suku Dayak Ma' anyan di Kalimantan dikenal upacara pembakaran mayat yang disebut ijambe.Upacara ijambe metiputi sem- 
bilan hari yang penuh dengan upacara-upacara, masing-masing disebut tarawen (mengumpulkan daun), ni'it uei (membelah rotan), narajak (mengikat kayu dengan rotan), mua rare (mengayam bambu), nahu (membuat arang kayu nyurat (menulis), nansaran (membangun panggung\}, munu (membunuh), dan mapul (membakar). Pada hari pertama, para pemuka suku menggambarkan pola-pola tradisional, berupa lengkungan dan sulur-suluran, pada bangunan perancah untuk tempat peti mayat ata $\underline{u}$ idaran. Kemudian pada hari keenam, nyurat, para pemuka suku kembali m':'.nggambarkan pola yang sama pada bangunan kayu yang akan dibakar . Bangunan ini disebut papuian. Bentuk idaran yang dibuat mirip perahu kccil, dan dengan selesainya bangunan ini dikatakan adlau (roh) siap melakukan petjalanan akhir menuju Datu Tanjung (tempat roh) (Hudson, I 1966: 366 - 393). Di samping, ketika mayat disimpan di rumah kematian di bagian belakangnya digantungkan kain sakral, manik-manik, perhiasan, dan bebcrapa benda lainnya. Perangkat yang disebut hanram itu dipasang agar roh orang yang mati merasa seperti di dalam rumahnya (Hudson.; 1966: 362). Jadi alat-alat upacara dan kegiatan penggambaran dalam upacara ljambe juga merupakan jaminan agar roh selamat hingga ke tempat yang dikehendaki.

Penggunaan kain sakral dalam upacara kematian di berbagai suku bangsa di Indonesia merupakan hal yang umum. Pada masyarakal Dayak Ngaju, kain sakral bergambar perahu arwah dipakai dalam upacaraupacara dan dipegang oleh pendeta sementara ia menyanyi dan bersyair (Scharer. 1963 : 11). Kain sakral dengan motif yang sama di S11matera Selatan digunakan dalam upacara inisiasi dan kematian. Kain ini dibentangkan di tempat tertentu saat upacara dilangsungkan (Hoop. 1949:306). Suku bangsa Toraja di Sulawesi juga menggunakan kain sakral dalam upacara kematian dan pemujaan roh nenek moyang. Kain-kain tersebut digantungkan di tempat tertentu, dipakai sebagai bendera dan panji, atau sebagai penutup mayat. Pola hias yang terdapat pada kain sakral tersebut antara lain kerbau, babi dan ayam jantan, serta bentuk geometris (Palm, 1979:257•- 9 ). Hiasan kerbau biasanya digambarkan dengan kepala herpaling dan tanduk yangjelas terlihat. Bentuk demikian dimaksudkan untuk mendapatkan kekuatan untuk melawan pengaruh jahat. Hal ini sesuai dengan anggapan bahwa kerbau adalah kendaraan arwah orang yang mati menuju ke dunia roh. Di samping itu kerbau juga .dianggap sebagai penjaga arwah orang yang mati (Palm, 1979 : 174 dan 198). Berdasarkan kenyataan tersebut, maka fungsi kain sakral tidak jauh berbeda dengan lukisan dinding gua. Kain sakral mungkin dipakai dengan pertimbangan praktis karena dapat dipakai berulang-ulang. 
Dari uraian yang telah dikemukakan pada bagian-bagian sebelumnya, tampak bahwa lukisan dinding gua, khususnya yang ditemukan dalam konteks penguburan, merupakan bagian yang penting dari seluruh upacara kematian. Lukisan dinding gua adalah sarana untuk menceritakan kembali mitologi tentang nenek moyang. Penceritaan kembali mitologi dimaksudkan sebagai magi untuk menjamin agar roh orang yang mati mampu melalui tahap peralihan dan menempati kedudukannya yang baru dengan selamat. Jadi, jika adat perawatan mayat merupakan ritus yang menitik beratkan pada pemeliharaan unsur jasmaniah orang yang mati, pembuatan lukisan dinding gua adalah ritus yang menekankan pada perawatan atau perhatian terhadap unsur rohaniahnya, yaitu roh orang yang mati. 


\section{DAFTAR KEPUSTAKAAN}

Adhy Asmara, 1980. Mengenal IrIan, Mutiara Hitam Indonesia. Yogyakarta: Nurcahya.

Baal, J. van. 1971. Symbols for Communication. Assen: Koninklijkke van Gocum \& Com. N.V.

Daeng, H. 1963. 'Orang Marind Anim' Penduduk Irian Barat. ed. Koentjaraningrat dan Harsya W. Bachtiar. Djakarta: Penerbitan Universitas.

Elkin, A.P. 1954. The Australian Aborigines : How to Understand Them. Sidney - London: Angus and Robertson.

Firth, R., . Mochtan, S. Puspanegara. 1966. Tjiri-tjiri dan Alam Hidup Manusia. Bandung: Penerbit Sumur Bandung.

Galis, K.W. 1948. 'Vondsted.....', Oudhedikundige Verslag 1948. Hlm. $13-17$

Harrison, Tom. 1958 'The Cave of Niah: A History of Prehistory'.

Sarawak Museum Journal, VIII No. 12, Desember 1958. Hlm. 549 - 595.

Heekeren, H .R. van. 1950 'The Rock Paintings and Other Prehistoric Discoveries near Maros (South West Celebes) 'Laporan Tahunan Dinas' Purbakala Tahun 1950. Hlm. 22 - 35.

Heekeren, H .R. van. 1972 The Stone Age of Indonesia. The HagueMartinus Nijhoff.

Holt, Claire. 1967. Art In Indonesia. Ithaca-New York: Cornell University Press. 
Hoop, A.N.J. Th. a. Th. van der. 1949. Ragam-ragam Perhiasan Indonesia. Koninklijke Bataviaasch Genootschap van Kunsten en Wetenschappen.

Hudson, A.B. 1966. 'Death Ceremonies of Paju Epat Ma'anyan Dayak' Sarawak Museum Journal XVI, no. 27, November 1966. Hlm. 342-426.

Koentjaraningrat. 1958. Beberapa Metode Anthropologi dalam Penyelidikan Masyarakat dan Kebudayaan di Indonesia. Djakarta: Penerbit Universitas.

Koentjaraningrat. 1977 Beberapa Pokok Anthropologi Sosial. Dian Rakyat.

Mulvaney, D.J. 1969. The Prehistory of Australia. London: Thames and Hudson.

Palm, Hetty Nooy. 1979. The Sa'adan Toraja, A Study of Their Social Life and Religion. VKI LXXXVII. The Hague - Martinus Nijhoff.

Peursen , C.A. van. 1976. Strategi Kebudayaan. Yogyakarta - Jakarta: Penerbitan Kanisius - BPK Gunung Mulia.

Rachmat Subagya. 1981. Agama Asli Indonesia. Jakarta: Yayasan Cipta Loka Caraka-Penerbit Sinar Harapan.

Read, Herbert. Pengertian Seni, diterjemahkan oleh Soedarsono S.P.

Read, Herbert. Pengertian Seni, diterjemahkan oleh Soedarsono S.P. Yogyakarta : STSRI Asri.

Roder, J. 1959. 'The Rockpaintings of the Mac Cluer Bay'. The Antiquity and Survival, 1, no. 5, 1959. Him. 387 - 400. 
Scaade, M.C. 1979. Kepercayaan Suku Dayak di Tanah Landak dan Tayan. Jakarta : Yayasan Idayu.

Scharer, Hans. 1963. Ngaju Religion : The Conception of God Among A South Borneo People. VKI transcription series 6. The Hague Martinus Nijhoff.

Soejono. P.S. 1963 'Prehistori Irian Barat'. Penduduk lrian Barat, ed. Koentjaraningrat dan Harsya W. Bachtiar. Djakarta: Penerbitan Universitas.

Soejono, R.P. 1977. Sistim-sistim Penguburan Pada Akhir Masa Prasejarah di Bali. Disertasi. 